\title{
Arqueología multicultural. Notas intempestivas
}

\author{
Multicultural archaeology. Untimely notes
}

\section{Cristóbal Gnecco}

Universidad del Cauca, Colombia

cgnecco@unicauca.edu.co

Recibido: 14-07-2012

Aceptado: 20-09-2012

\begin{abstract}
RESUMEN
En las dos o tres últimas décadas el multiculturalismo ha puesto en marcha cambios profundos, especialmente con respecto a la organización de la sociedad y la manera como es representada la historia. La disciplina ha sido influida por el nuevo orden, tanto que merece ser llamada arqueología multicultural. El análisis de la manera como los arqueólogos se relacionan con el "público" puede servir para reflexionar sobre las limitaciones y los problemas que acosan la lógica multicultural (nuevos regímenes de alterización a través de exigencias de autenticidad y originalidad; tolerancia; distancia; corrección política). Este artículo busca esbozar las características de la arqueología en el multiculturalismo y cómo se relacionan con asuntos más amplios, como el entendimiento intercultural y la descolonización.
\end{abstract}

Palabras Clave: Arqueología. Multiculturalismo. Regímenes de alteridad.

\begin{abstract}
In the last two or three decades multiculturalism has set in motion profound changes, especially regarding the organization of society and the way history is represented. The discipline has been so shaped by the new social order that a multicultural archaeology has emerged. The analysis of how archaeologists nowadays relate to the "public" can serve to reflect on the limitations and problems that beset the multicultural logic (new regimes of othering through demands of authenticity and originality; tolerance; distance, political correctness). This paper aims to outline what a multicultural archaeology is and how it relates to wider topics such as intercultural understanding and decolonization.
\end{abstract}

KEY WORDS: Archaeology. Multiculturalism. Regimes of Othering.

Sumario: Introducción. Noticias de eventos ya acontecidos. Debates. Escenarios. 


\section{Introducción}

Me gustaría creer que la arqueología contribuye a la transformación social. Me gustaría argumentar que su responsabilidad hacia la sociedad (la misma que financia la educación pública, los institutos de investigación, los museos y las becas) la hace sensible, e incluso comprometida, con la construcción de un mundo mejor. Pero no puedo hacerlo; no en este momento. Ante los cambios experimentados en el mundo en las últimas décadas, la arqueología ca1la. Ante la reorganización de la sociedad, que dio al traste con los Estados nacionales, sigue metida en la trinchera - no la del combate ideológico sino la de la excavación esotérica. Allí ha permanecido, alimentando un autismo irresponsable y deliberado, sin salir a la luz del contexto; reproduciendo, hasta la náusea, una indagación auto-referencial que hace del pasado un lugar para huir de los acontecimientos que nos hacen, nos exigen y nos condenan. Los arqueólogos huyen, seguro, pero ¿de qué? Huyen de las palabras que dijo André Breton el 7 de junio de 1946 en una velada en homenaje a Antonin Artaud, recién liberado del manicomio de Rodez: "me parece motivo de burla toda forma de compromiso que no llegue a este objetivo triple e indivisible: transformar el mundo; cambiar la vida; rehacer, completamente, el entendimiento humano." No se han percatado (o, si lo han hecho, se han guardado bien de decirlo) de que los discursos relacionados con la creación y el funcionamiento de las sociedades nacionales han perdido impulso y significación con la emergencia del multiculturalismo, que tiene temblando a los principios fundamentales de las sociedades modernas, especialmente la construcción de colectividades unificadas (las sociedades nacionales) en términos de cultura, lengua e historia. El multiculturalismo ha puesto en movimiento cambios profundos en la organización de la sociedad, ahora predicada sobre la coexistencia de grupos diferentes - convencionalmente referidos como diversidad cultural. La lucha moderna, muchas veces violenta, por la unificación social ha sido abandonada. ${ }^{1}$

Pero el multiculturalismo no es una reorganización inocente de la sociedad. Ha sido ampliamente criticado por quienes piensan que promueve la diversidad cultural pero ignora las necesidades y expectativas de lo diferente. La diversidad cultural es canalizada para adaptarla a las exigencias multiculturales en un vacío político. Además, la celebración de la diversidad, que estimula la proliferación de identidades locales y específicas, debilita las identidades más incluyentes, vinculantes y fuertes. En un mundo de identidades fragmentadas, con independencia de lo fuertes que sean en términos individuales, sigue imperando el sistema.
Lo mismo sucede con la arqueología contemporánea: aunque tolera representaciones diferentes del pasado e, incluso, la ampliación de su despliegue escénico, su tejido metafísico y ontológico permanece intocado. Ha sido tan moldeada por el nuevo orden social que ha surgido una arqueología multicultural. Para mantener el ritmo de los cambios multiculturales (que, por cierto, no ha defendido ni promovido pero a los cuales se tiene que acomodar) ha hecho, básicamente, cuatro cosas: (a) abrir su práctica a la participación de actores locales (en las investigaciones y en las tomas de decisión); (b) abrir los espacios de circulación de sus productos (sobre todo con la promoción de museos locales y de medios impresos y audiovisuales); (c) incluir/ usar interpretaciones históricas no occidentales en su horizonte hermenéutico; y (d) renunciar al control exclusivo de algunos temas disputados, sobre todo a través de la repatriación selectiva de restos biológicos y culturales.

La jugada maestra de la arqueología en tiempos multiculturales — cambiar para seguir haciendo lo mismo - imita lo que hicieron los antropólogos textualistas de la década de 1980 (esos que localizaron la culpa colonial en el texto) y sobre quienes Johannes Fabian (1990: 761) escribió: “¿Debemos temer que lo que parece crisis es sólo un montón de ruido hecho por los antropólogos que se reagrupan en su intento por salvar los privilegios del representador?" Salvar privilegios: de eso se trata. Los arqueólogos, miembros de una minoría cognitiva privilegiada, no quieren perder los privilegios que les otorga ser los dueños de una forma de representación que, como mucho, están dispuestos a compartir (con los indígenas, por ejemplo, sus némesis vueltos de pronto aliados) pero, jamás, a cambiar de veras. Parafraseando a Fabian (1990), los "cambios" experimentados por la arqueología multicultural son tanto síntoma como terapia. Más aún, la aceptación de la arqueología por agendas disidentes - las arqueologías feministas e indígenas son las mejor conocidas-, edificadas sobre la idea de que el problema no es la disciplina sino la manera como ha sido usada, ha fortalecido y endurecido su estructura filosófica. Pero hay sujetos que la impugnan y la ponen al descubierto, exponiendo su funcionamiento en tiempos multiculturales y mostrando cómo continúa contribuyendo a la reproducción de asimetrías en las representaciones históricas.

\section{Noticias de eventos ya acontecidos}

La arqueología se relacionó con los Estados nacionales por medio de la creación del ser nacional. Proporcionó la profundidad temporal y el simbolismo 
unificado sobre los cuales se predicó la sociedad moderna. Dio a la nación la continuidad necesaria para que no apareciera como la transgresión descarnada de lo que había reemplazado. Lo nuevo (modernidad, Estado-nación, sociedad nacional) encontró en lo arqueológico (discursos sobre antigüedades y ancestros basados en objetos) una densidad profunda. ¿Qué significa ser nacional en términos arqueológicos? Significa modernizar la forma de contar el tiempo, hacerlo trascendente (objetivo, neutral), llevar un colectivo (la sociedad nacional) y una singularidad (el individuo moderno) a reconocerse mutuamente como totalidad y parte y unirlos en un espacio ceremonial, mnemónico. El tiempo moderno desempeñó tres funciones: fue una medida de progreso (la sociedad supo dónde estaba, hacia dónde iba y de dónde venía); fue un medio de control (los sujetos tuvieron que ajustarse a un comportamiento temporal que estableció un origen, una ruta y un destino); y fue señal de un intercambio simbólico (entre la sociedad y el conocimiento experto). La arqueología fue creada por la modernidad para producir una temporalidad nueva, apropiada para la emergencia de un nosotros nacional (profundo, homogéneo, proyectivo y compartido). La alteridad fue desterrada de ese nosotros, como en muchos otros campos simbólicos de las nuevas naciones (educación, salud, ley). El salvaje arquetípico (la contraparte negativa del nosotros moderno) fue construido como una entidad externa a la modernidad, su lado oscuro, que debía ser incorporada o eliminada.

Por más de dos siglos la arqueología y el nacionalismo crecieron en la misma senda. Pero hace poco más de dos décadas fue reorganizado el campo simbólico de la modernidad. Como resultado de esa reorganización el salvaje dejó de ser castigado. Sorprendentemente, ahora fue elevado a elemento constitutivo de la nueva sociedad que se creó desde entonces: diversa, múltiple y plural. El multiculturalismo asumió que el salvaje como diversidad abandonaría su papel de némesis de la modernidad y que permitiría ser domesticado y organizado; el erotismo político de la modernidad, mediante el cual la alteridad fue fusionada con la sociedad nacional, fue reemplazado por la coexistencia tolerante de lo diverso. La promoción de la diversidad cultural, impensable durante los tiempos modernos, ahora es un imperativo categórico, en un sentido plenamente kantiano - un mandato autónomo y auto-suficiente.

Las palabras claves que ligan las reformas multiculturales son reconocimiento, autonomía y límites, especialmente con respecto a los grupos étnicos. El reconocimiento ha sido anunciado, desde comienzos de la década de 1980, como la huella más importante de la nueva sociedad. De hecho, como
Charles Taylor (1993: 61) señaló, en esa época ocurrió un cambio dramático, el paso de la política de la dignidad igualitaria a la política del reconocimiento: "Con la política de la dignidad igualitaria lo que se establece pretende ser universalmente lo mismo, una 'canasta' idéntica de derechos e inmunidades; con la política de la diferencia lo que pedimos que sea reconocido es la identidad única de este individuo o de este grupo, el hecho de que es distinto de todos los demás. La idea es que, precisamente, esta condición de ser distinto es la que se ha pasado por alto, ha sido objeto de glosas y asimilada por una identidad dominante e igualitaria." Pero ese reconocimiento no debía ser una simple declaración: "Pero la otra exigencia que tratamos aquí es que todos reconozcamos el igual valor de las diferentes culturas; que no sólo las dejemos sobrevivir, sino que reconozcamos su valor" (Taylor 1993: 94-95; cursivas en el original). Sin embargo, después de casi tres décadas de políticas multiculturales está claro que la exigencia de Taylor fue ignorada: la convivencia multicultural de la diversidad cultural no se ha traducido en el reconocimiento del valor de lo diferente sino, simplemente, en el reconocimiento de su existencia, que ha sido organizada y, en gran medida, aislada.

Variando en intensidad y grado, las reformas multiculturales pretendieron asegurar o consagrar la autonomía territorial, legal, educativa, administrativa, fiscal y lingüística de grupos culturalmente diversos. Pero debido a que la autonomía dentro de las fronteras nacionales siempre fue un dilema para la teoría política moderna, el multiculturalismo tomó las medidas necesarias para que no fuera una amenaza para las sociedades cohesionadas que la modernidad forjó con tanto trabajo. Como resultado, la autonomía se otorga dentro de ciertos límites. Taylor (1993: 93) lo señaló de esta manera: "el liberalismo no puede ni debe atribuirse una completa neutralidad cultural. El liberalismo es, también, un credo combatiente. La variable tolerante que apruebo, así como sus formas más rígidas, tiene que establecer un límite." La autonomía legal, por ejemplo, es otorgada a minorías con concepciones y prácticas de justicia diferenciales, a veces muy lejos de la justicia moderna, pero sólo puede ser ejercida dentro de límites culturales y territoriales; sólo puede ser aplicada a ciertos individuos y en ciertos lugares.

El reconocimiento, la autonomía y los límites funcionan juntos, en una relación tensa pero productiva, para construir las nuevas sociedades postnacionales. Pero un campo simbólico prominente, el de la historia, fue (aparentemente) soslayado por la reorganización multicultural. Las concesiones multiculturales establecen los límites dictados por las políticas estatales. Por eso hay bordes que no 
pueden cruzar ciertas autonomías: la reivindicación de autonomía nacional dentro de la nación es una de ellas; la historia es otra. La historia todavía es un campo - controlado por el Estado y por las disciplinas académicas - para el despliegue de un nosotros colectivo que, sin embargo, se vuelve una categoría cada vez más borrosa en tiempos multiculturales. Si la arqueología moderna tenía más o menos clara su relación con el nacionalismo, ahora su casa está desordenada; si antes administró discursos que trataban con un Otro externo a la modernidad (el salvaje arquetípico), ahora ignora qué clase de discursos administra cuando ese Otro ya no es exterioridad sino interioridad constitutiva. ¿Va a seguir contando la historia de un nosotros homogéneo, estático y disciplinado, aun cuando la alteridad se esfuerza por construirse en la diferencia y la disyunción y aun cuando florece por doquier la diversidad cultural predicada por el multiculturalismo? O, más bien, ¿va a escribir una historia nueva (múltiple, plural) en la que los Otros antes desterrados también estén representados, esos mismos Otros que ahora luchan por fortalecer un lugar y un tiempo, sin importar que lo hagan reivindicando agendas abiertamente anacrónicas para Occidente? En cualquier caso, la situación es compleja para la arqueología. Si opta por la primera posibilidad estará afirmando que el multiculturalismo bien puede haber llegado pero que nada ha cambiado en la disciplina. Esa afirmación tendría apoyo del Estado, que no oculta que su aparato mnemónico está intacto - una estrategia que sería anacrónica sino fuera calculada; los museos centrales, por ejemplo, todavía son nacionales. Si opta por la segunda, esto es, una historia múltiple y plural, sea lo que sea, estará navegando en aguas desconocidas. Eso no sería un gran problema si no fuera porque allí, en la profundidad de lo desconocido, pueden estar esperando sorpresas no deseadas. Por un lado, la multiplicidad puede significar dos cosas: o historias diferentes que viven lado a lado - lo que es una utopía ingenua, dada la operación de la hegemonía - o una historia-sombrilla, de alguna manera mimética del modelo nacional, bajo la cual florecen varias particularidades. Por otro lado, una alteridad radical bien puede querer que explote lo poco que queda de las historias nacionales; en ese caso, reconstruir la totalidad destrozada sería una tarea tremenda, seguramente inútil.

Ante esos escenarios tan complejos la arqueología decidió ser salomónica y optó por una vía intermedia, que cree segura y cómoda: ni la reproducción de una historia nacional unificada ni una historia múltiple, desconocida y probablemente imposible. El curioso enfoque que ha adoptado mezcla un poco del viejo positivismo, aunque matizado, con un poco de un nuevo constructivismo.
Dice que el pasado es totalmente conocible por medios científicos pero acepta que es una construcción histórica; esta aceptación implica la legitimidad de diferentes versiones del pasado. A su manera, sigue la exigencia contemporánea de justicia social que se ha vuelto una necesidad para muchos e, incidentalmente, también un tropo (vacío, por lo demás). Se compromete con la diversidad (no casualmente ávida de esa justicia) sólo marginalmente, a regañadientes. Pero no está tan comprometida con otras agendas, después de todo, y más bien sigue el camino trillado y ortodoxo del positivismo, observa con desdén (pero usa selectivamente) las diferentes historias que el capitalismo postmoderno le pide tolerar y se regodea existiendo (con la seguridad que obtiene del aparato institucional) en un mundo de historias separadas, domesticado y explotado por el mercado.

Este dilema - la mezcla de positivismo + constructivismo - no es nuevo. Ya ha sucedido antes, y no pocas veces. Quizás fue inaugurado por la insistencia marxista en el carácter histórico de la superestructura y, al mismo tiempo, en la universalidad del materialismo histórico. La teoría crítica trató de resolver este cul-de-sac postulando la relatividad de las verdades superestructurales, controladas por la reflexión crítica y por su lugar en las realidades políticas. Algunos arqueólogos han hecho suya esa salida. Moshenska (2009: 47), por ejemplo, señaló que "la arqueología pública, en el sentido más amplio, es esa parte de la disciplina que se preocupa por estudiar y criticar los procesos de producción y consumo de las mercancías arqueológicas." Pero para la mayor parte de la arqueología el dilema ha pasado a ser un coctel (improbable, pero poderoso) que define los contornos de la arqueología multicultural, una estrategia de práctica disciplinaria que, desde la distancia (no la neutralidad de la época científica sino el cinismo de la corrección política), permite otras versiones históricas al mismo tiempo que endurece su intervención. La arqueología se ha adaptado a los mandatos multiculturales adoptando una apariencia más democrática y tolerante. Mientras tanto, otras historias (basadas o no en las narrativas arqueológicas) luchan por encontrar su camino. El resultado neto es que la fragmentación histórica vive junto con una disciplina académica endurecida y financiada por el Estado y que, gracias al trabajo ideológico y al consentimiento hegemónico, todavía reina. Un producto puramente multicultural.

Al endurecimiento multicultural de la arqueología qua disciplina occidental han contribuido las llamadas arqueologías alternativas. Una de ellas, la arqueología indígena (Watkins 2000; Smith y Wobst 2005), se aparta de ciertas prácticas arqueológicas, 
especialmente coloniales, pero acepta los principios fundacionales de la disciplina - aunque posiciona sus propias agendas. Incluso ofrece disolver dicotomías radicales: "La arqueología indígena quizás está en una posición única para desafiar, creativamente, las categorías hegemónicas y para desmantelar marcos binarios, como 'indio' y 'arqueólogo' " (Colwell-Chanthaphonh et al. 2010: 231). A pesar de las buenas intenciones, hacer desaparecer una dicotomía importante para la confrontación anticolonial unifica y solidifica a la arqueología al hacerla más democrática. Las categorías hegemónicas no serán desafiadas desmantelando los marcos binarios; serán reforzadas. Si la dicotomía indígenasarqueólogos fue excluyente e irreconciliable hasta hace poco, la arqueología indígena busca disolverla. El trabajo teórico que siguió a la publicación del libro de Joe Watkins (2000), que "ha comenzado, explícitamente, a enmarcar la arqueología indígena como un esfuerzo por desafiar los sustentos colonialistas de la disciplina" (Colwell-Chanthaphonh et al. 2010: 228), está basado en el implícito de que una arqueología "descolonizada" puede retener el núcleo moderno de la disciplina. ¿Cómo pueden ser definidas las arqueologías alternativas "como discursos y prácticas múltiples sobre las cosas de otro tiempo" (Hamilakis 2011: 408) si retienen el fundamento ontológico de la concepción moderna sobre los tiempos pasados? ¿Ese "otro tiempo" puede ser efectivamente promulgado a través/desde la ontología moderna? Difícilmente, porque uno de los principios básicos de la arqueología indígena, como lo señaló una de sus principales proponentes, establece que "Mientras el enfoque y las especificidades pueden variar, un hilo común entre las arqueologías indígenas que he observado es la incorporación de, y el respeto por, las experiencias y las epistemologías de los grupos indígenas globalmente" (Atalay 2008: 29). Por esa razón la arqueología indígena se ve a gatas para ser alternativa de algo. Si lo indige$n a$ quiere retener su postura anti-moderna (o, por lo menos, el deseo de ser una alternativa a la modernidad), donde yace su poder político y su sentido utópico, no puede ser un adjetivo de la arqueología (una disciplina moderna practicada por indígenas) sino un sustantivo que implica cosmologías distintas en sus propios términos. En suma, las arqueologías alternativas que retienen los principios básicos de la disciplina reafirman la cosmología occidental. Son lo mejor que le ha pasado a la arqueología desde el rompimiento del consenso científico en la década de 1960: el Otro ya no es su némesis sino su aliado.

Este rápido esbozo de la arqueología multicultural no estaría completo si dejo de lado al mercado. Llegar al público, uno de sus lemas, equivale a llegar al mercado mientras preserva una actitud democrática, abierta y tolerante. ¿Acaso el entusiasmo con el cual la arqueología abraza el mercado - en operaciones de contrato, museos, negocios patrimoniales y parques históricos- no es un síntoma de su incomodidad en la escena multicultural? En vez de enfrentar los dilemas creados por su apertura de campos de representación histórica antes cerrados (una verdadera caja de Pandora), se entrega, plácidamente, al mercado y difiere la confrontación de otras realidades con la esperanza de que ese diferimiento dure para siempre.

\section{Debates}

Las características que definen la arqueología multicultural también sirven para bosquejar los problemas más acuciantes que enfrenta en la actualidad; esos problemas pueden ser vistos más juiciosamente, sin embargo, a la luz de las críticas más generales levantadas contra el multiculturalismo.

\section{Una crítica del multiculturalismo}

La coexistencia de culturas diversas es una marca de fábrica del multiculturalismo, una política de la diversidad basada en el reconocimiento de Otro estereotípico, virtual y segregado. El "otro real" (que responde de maneras diversas, no siempre pacíficas, democráticas ni humanistas, a las presiones del capitalismo salvaje, a la velocidad de los flujos globales y a la violencia postideológica) debe dar paso, sin disonancias, al "otro imaginado" (que vive su vida bucólica y exótica en el mundo de la tolerancia y la separación). Como señaló Slavoj Žižek (1998: 157) de una manera brutal: "La 'tolerancia' liberal excusa al Otro folclórico, privado de su sustancia (como la multiplicidad de 'comidas étnicas' en una megalópolis contemporánea) pero denuncia a cualquier Otro 'real' por su 'fundamentalismo,' dado que el núcleo de la Otredad está en la regulación de su goce: el 'Otro real' es, por definición, 'patriarcal,' 'violento,' jamás es el Otro de la sabiduría etérea y las costumbres encantadoras. Uno se ve tentado aquí a reactualizar la vieja noción marcuseana de 'tolerancia represiva,' considerándola ahora como la tolerancia del Otro en su forma aséptica, benigna, lo que forcluye la dimensión de lo Real del goce del Otro." Conceptos devastadores, en verdad: regulación del goce de la alteridad; tolerancia represiva; estigmatización y, al mismo tiempo, promoción del primordialismo. El multiculturalismo organiza las diferencias, nominándolas y creándolas desde el Estado, los organismos multilaterales, las ONGs, la academia. El "otro real" es reprimido por 
su reflejo virtual. Otra vez Žižek (1998: 172): “en el multiculturalismo existe una distancia eurocentrista condescendiente y/o respetuosa para con las culturas locales, sin echar raíces en ninguna cultura en particular... el multiculturalismo es una forma de racismo negada, invertida, autorreferencial, un 'racismo con distancia:' 'respeta' la identidad del Otro, concibiéndolo como una comunidad 'auténtica' cerrada hacia la cual él, el multiculturalista, mantiene una distancia que se hace posible gracias a su posición universal privilegiada."

El "otro virtual" neutraliza el activismo de lo diferente imponiéndole límites, legales y de otro tipo, y entregándolo al mercado - que lo trata tan sólo como diversidad, controlada y promovida como auténtica y pura. La tolerancia de las historias no académicas por la arqueología multicultural está atravesada por la exigencia de autenticidad, produciendo intransigencias canónicas que establecen (nuevos) límites a la legitimidad retórica. Por ejemplo, muchos arqueólogos fustigan la falta de autenticidad de los usos indígenas contemporáneos del pasado porque son esencialistas y porque reclaman continuidades históricas que la arqueología y la "etnohistoria" consideran espurias. Esta lucha retórica por la autenticidad no es de poca monta y enfrenta actores que hablan desde posiciones situadas en lados opuestos del río de la identidad. En este asunto los indígenas (reconocidos, legitimados, santificados y promovidos por los discursos expertos) deben ser como las definiciones occidentales quieren que sean: sujetos de una cultura auténtica y pura y guardianes de la naturaleza y de la historia. La autenticidad exigida a los indígenas por los arqueólogos multiculturales los carga con el peso de la culpa occidental porque ve en las comunidades nativas, que cree (y quiere) unidas orgánicamente con su pasado (un pasado auténtico), a los actores capaces de recuperar y potenciar el sentido de unidad y de armonía con la historia, redimiendo las depredaciones temporales de la postmodernidad: "En esta trayectoria del discurso edénico que va del Paraíso Encontrado al Paraíso Perdido la figura del indio inmanente ha sido un instrumento crucial para el blanco trascendental. Porque es el hombre blanco quien 'encuentra' el Paraíso, lo transforma hasta arruinarlo y, de nuevo a través de su volición, rescata a la Tierra de su propia rapacidad. Como agente soberano del mundo el hombre blanco ha reducido a los indios a meros rehenes de su terrorismo económico" (Ramos 1994: 79).

La exigencia de autenticidad, siempre circunstancial y maleable, hace aparecer a las historias locales como uno de los lugares posibles (quizás el más posible) de reactivación del sentido del tiempo que la postmodernidad pretende aniquilar. En una paradoja que sólo puede ser postmoderna las historias indígenas antes apropiadas y transformadas por la historia nacional ahora son valoradas como discursos de continuidad y sacralidad alternativos a la brutal deshistorización del pasado. Esta demanda de autenticidad procede de la nostalgia imperialista; los agentes del colonialismo "normalmente exhiben nostalgia por la cultura del colonizado como era 'tradicionalmente' (esto es, cuando la encontraron por primera vez). La peculiaridad de su lamento es, desde luego, que los agentes del colonialismo suspiran por las formas de vida que alteraron o destruyeron intencionalmente... una clase particular de nostalgia, usualmente encontrada en el imperialismo, en la cual las personas deploran la muerte de lo que ellas mismas han transformado" (Rosaldo 1993: 69). Esta nostalgia por algo perdido que nunca se tuvo (al fin y al cabo, las historias indígenas que ahora se ensalzan antes fueron parias ignorados y negados) es una huida hacia la naturaleza y el pasado; exotiza al otro mientras busca limitar su despliegue. No en vano el proyecto cultural del multiculturalismo es "aprovechar y redirigir la abundante energía del activismo de los derechos culturales, más que oponerse a ella directamente" (Hale 2002: 498). El multiculturalismo, con su estética de la nostalgia y de la indiferencia, se siente libre de huir de su propia historia al mismo tiempo que lega en otros (en los nativos) la constitución de sentidos históricos que alaba, capitaliza, mercantiliza y discrimina.

La equivalencia entre los discursos multiculturales del medio ambiente y del pasado es notoria. Parafraseando a Astrid Ulloa (2004) llamaré nativo histórico al guardián altamente calificado de la historia por auténtico y continuo. Pero cuando los indígenas se aventuran fuera del nuevo canon de la representación multicultural (más estrecho y vigilado que los cánones colonial y moderno) su autenticidad se pone en entredicho y sus derechos son limitados: "El indio bueno, estoico y politizado es entonces velado con una legitimidad que es tan diáfana como efímera porque puede, rápidamente, convertirse en desprecio si pisa la línea estrecha dibujada por sus sostenedores blancos" (Ramos 1994: 86). El nativo histórico es auténtico mientras siga los senderos de la historia "cierta" (la de las disciplinas expertas), no "invente" tradiciones de la "nada" y use el pasado en la construcción de identidad (jamás para otros fines más mundanos).

La distancia entre diversidad y diferencia es la principal limitación del multiculturalismo y es tanto una característica como un síntoma. De hecho, las décadas que siguieron a la última guerra mundial, pero especialmente las tres últimas, han presenciado el abandono generalizado de categorías peyora- 
tivas y estigmatizantes (razas inferiores, primitivas, subdesarrolladas) y el fortalecimiento de la relativización culturalista (culturas diferentes) que desactiva la organización de base, des-racializa el racismo (pero lo conserva intacto) y reifica/funcionaliza la heterogeneidad para dulcificar las desigualdades. Como Claudia Briones (2005: 22) señaló: "Puesto que las relaciones sociales que recrean procesos de alterización se presentan y explican desvinculadas de la organización del capital y el poder internacional y nacional, la diferencia cultural emerge como propiedad cuasi-ontológica." La idea multicultural de diversidad quiere que la heterogeneidad sea entendida como un "mosaico de identidades monocromas" (Brubaker y Cooper 2001: 33), eliminando las especificidades históricas, los procesos de alterización, las asimetrías y las relaciones de poder. Por eso es necesario establecer la distancia entre $d i$ versidad - la que promueve el multiculturalismo: quieta e inocua, exótica, complaciente, organizada y mercantil-y diferencia - la "constante producción y emergencia de sujetos en el embate de sus antagonismos y tensiones" (Segato 2007: 27-28) para entender a la alteridad en su acontecimiento.

Como si este ya no fuera un problema suficientemente difícil de resolver, el multiculturalismo está plagado de tensiones constitutivas. Las más prominentes de ellas son la contradicción entre derechos colectivos e individuales y la autonomía otorgada a las simbolizaciones distintas de la sociedad y de la vida. Aunque la autonomía ha sido controlada con el establecimiento de límites, sigue siendo potencialmente explosiva. La "solución" que han adoptado las sociedades multiculturales para resolver estas tensiones es el diferimiento y, cuando las circunstancias son demasiado acuciantes, la casuística.

\section{Por una crítica de la arqueología multicultural}

A la luz de las críticas al multiculturalismo se pueden ver, acaso mejor, las críticas a la arqueología multicultural con respecto a sus características principales: (a) práctica abierta; (b) circulación ampliada de los discursos arqueológicos; (c) expansión de la hermenéutica disciplinaria; y (d) abandono del control de ciertos asuntos. Primero, la práctica abierta que abandera sólo ha permitido que los actores locales sean miembros de los grupos de investigación o, como mucho, que sean entrenados en la disciplina. Esa apertura ha sido enmarcada bajo el rótulo de "colaboración," pero las relaciones de poder no están en juego. La mayoría de los arqueólogos se contenta con ofrecer migajas culturales (un museo local, un video, una cartilla) mientras preservan el control de temas fundamentales (diseños de investigación, destino de los hallazgos, produc- ción y diseminación de narrativas). Segundo, la circulación ampliada de los discursos arqueológicos -que, junto con la colaboración, forma la columna vertebral de la llamada arqueología pública - ha tenido dos resultados: reproduce el canon disciplinario con mayor prolijidad y aumenta la reificación y objetivación del pasado, como en el caso de los museos locales. Tercero, la expansión de la hermenéutica arqueológica alcanzada mediante la incorporación de concepciones no occidentales de la historia ha enriquecido el potencial explicativo de la disciplina pero no ha producido entendimientos interculturales. Esa expansión interpretativa, que muchas veces recurre a cosmologías ajenas que producen curiosos híbridos argumentales (por ejemplo: objetos vivos, con agencia, en medio de rígidos marcos funcionales), profundiza la arrogancia logocéntrica pero no busca forjar relaciones no jerárquicas; como resultado, la diferencia histórica (interpretaciones diferenciales del pasado, incluyendo qué es el pasado) es un mero instrumento para una arqueología más vigorosa. Cuarto, renunciar al control de ciertos asuntos significa eso, precisamente: ciertos asuntos y bajo ciertas circunstancias. Esta característica se ha constituido, con frecuencia, a través de la repatriación selectiva de restos biológicos y culturales. Aunque la repatriación es un recurso importante cuyo potencial para los movimientos sociales es incuestionable, vale la pena preguntar por qué se ha vuelto tan central y visible para la arqueología. Como si respondiera a esta pregunta Chris Gosden (2001: 258) señaló que "La agencia de los pueblos indígenas en la creación de formas coloniales en el pasado tiene un eco fuerte en la actualidad, cuando las exigencias para que los arqueólogos creen visiones de la historia más sensibles localmente están respaldadas por la legislación. Esto significa que la investigación actual debe ser un proyecto colaborativo entre los arqueólogos y las comunidades locales y que esto sólo puede ocurrir una vez que las injusticias del pasado hayan sido retomadas, lo que generalmente significará el retorno de esqueletos o cultura material que se considera que fueron inapropiadamente obtenidos, guardados o exhibidos" (añadí las cursivas). La repatriación es un tema muy debatido en la arqueología contemporánea no tanto porque devolver sitios, cosas y restos debilite el fundamentalismo de muchos arqueólogos sino porque se ha vuelto el sitio ideal para expiar la culpa colonial. Los arqueólogos están firmemente convencidos de que la repatriación curará las injusticias del pasado. Su sacrificio es menor: devolver (o compartir) unas pocas cosas para preservar sus privilegios cognitivos, su mirada logocéntrica, su sólida red narrativa, su impacto mnemónico. 
En suma, la arqueología multicultural participa del incoherente discurso histórico del multiculturalismo, cuyo nosotros nunca había sido tan borroso (¿o es en exceso coherente y su aparente incoherencia es, apenas, una tensión más en la ya larga lista de tensiones postmodernas?). Además, difiere la solución de las tensiones que ha contribuido a crear, como la autonomía de las representaciones históricas; lo hace tratando las diferentes concepciones de la historia como mera diversidad aislada - apropiada para la explotación mercantil, como muestra el boom de la memoria (Martín 2000)-, sin consecuencia alguna para la sociedad en general.

\section{Escenarios}

Los tiempos que corren - postmodernos, transmodernos, postindustriales - muestran la nueva cara de la sociedad burguesa, en la cual las identidades que eran antagonistas y excluyentes ahora coexisten en el plácido (pero probadamente explosivo) pacifismo de la relajación multicultural. Una amplia variedad de etnias y géneros ahora es parte del paisaje del mundo, donde antes sólo hubo individuos heterosexuales y nacionales. Esa coexistencia tan improbable es el mayor logro del capitalismo contemporáneo - aún más que haber reemplazado las mercancías por el deseo en la imaginación de la gente.

Hasta hace dos décadas las historias no occidentales y su manera de relacionarse con la materialidad y el patrimonio eran desconocidas para los Estados modernos y para la academia; el campo simbólico de la historia era estable y unificado alrededor del ser nacional. ¿Qué las hace visibles ahora? Las luchas anti-coloniales, sin duda, pero también una razón más sutil: la búsqueda multicultural de la diversidad, la apropiación y neutralización de lo diferente que, en otras circunstancias, podría desestabilizar lo que ha sido estabilizado a fuerza de hegemonía y trabajo ideológico. (En este nuevo acto hegemónico, consentido por lo diferente, medra el mercado.) En este escenario, aparentemente abierto y horizontal, el establecimiento arqueológico "reformado" se siente feliz de conceder lo que más quiere a actores previamente marginados: la coherencia epistémica disciplinaria. Sus ganancias son numerosas: sigue practicando la arqueología como ha sido conocida (no cambia nada de su tejido metafísico); lo hace en público (generosamente); se siente más democrático (al compartir); se acerca a lo que solía llamar el salvaje, apaciguando sus deseos y convenciéndose de que la cercanía disciplinaria se traduce en coalescencia espacial, temporal y cultural.

Pero la disonancia y la confrontación no han cesado de existir y pueden ser miradas examinando la relación entre la arqueología y los pueblos indígenas, todavía sus oponentes más fieros. Para empezar, los pueblos indígenas y los arqueólogos piensan, sienten y quieren cosas distintas de su mutua concurrencia al escenario arqueológico. Para los arqueólogos está claro: la aceptación indígena de una arqueología abierta y democrática es su mejor esperanza para el futuro de la disciplina. Los arqueólogos multiculturales están encantados de compartir su conocimiento con la masa lega - esta vez vestida con atuendos étnicos. Su movida ilustrada les place mucho porque disfrazan como altruismo y corrección política su indeclinable compromiso con la cosmología Occidental. Por otra parte, el posicionamiento de los pueblos indígenas frente a la arqueología no es tan consensual. Algunos valoran los procesos y resultados arqueológicos si son parte de sus agendas, considerando que los objetos y los rasgos vueltos arqueológicos por los discursos académicos o apropiados por las comunidades pueden servir para fortalecer su historia. Otros confrontan la arqueología abiertamente y rechazan cualquier posibilidad de transacción con ella. Una revisión, incluso rápida, de la distribución geográfica de esas dos posiciones antitéticas muestra que la primera es más frecuente en los grupos indígenas de las democracias industrializadas mientras la segunda caracteriza a los grupos del viejo Tercer Mundo. Esa distribución no es aberrante; responde a la efectividad diferencial de las políticas multiculturales y a lo exitosas que han sido en la construcción de hegemonías fuertes - alcanzadas más completamente en los países donde el nacionalismo fue más agresivo y triunfante.

Quienes se enfrentan a la arqueología y no quieren saber nada de ella levantan su voz desde una emergencia discursiva, desde la distancia, incluso desde una exterioridad asumida. Exponen y retan lo que ha hecho Occidente y arrastran a sus instituciones a la pelea, incluyendo a la academia. La confrontación con Occidente no es nueva - tiene varios siglos - pero ganó más coherencia y fuerza desde la década de 1950, comenzando con las guerras anticoloniales en África. Ha aumentado su ritmo e intensidad en la escena multicultural, allí donde concurren actores con agendas opuestas. El multiculturalismo abre el mundo de la representación y da acceso a otros sujetos representadores; quiere, sin embargo, que la representación sea un mero epifenómeno de relaciones jerárquicas que busca preservar. Las representaciones múltiples del pasado, incidentalmente liberadas por la autonomía inherente en las reformas multiculturales (aunque la autonomía histórica está conspicuamente ausente de los mandatos constitucionales y legales), son separadas del mundo del poder. Pero ¿qué pasa si 
consideramos la representación como praxis, como sugirió Johannes Fabian (1990)? La praxis es hacer, acontecimiento; es la posibilidad de que la presencia del otro sea sentida, vivida, aceptada, por fuera de la representación como epifenómeno una representación que, en cualquier caso, ha sido predicada sobre su ausencia. Si un mundo plural, horizontal y abierto (un mundo histórico y de otras maneras) puede significar más que el inocuo pluralismo relativista, ese significado puede encontrarse en la lucha por la alteridad radical. Mejor que lo diga Rita Laura Segato (2007: 18): "la lucha de los movimientos sociales inspirados en el proyecto de una 'política de la identidad' no alcanzará la radicalidad del pluralismo que pretende afirmar a menos que los grupos insurgentes partan de una conciencia clara de la profundidad de su 'diferencia,' es decir, de la propuesta de mundo alternativa que guía su insurgencia. Diferencia que aquí entiendo no con referencia a contenidos substantivos en términos de 'costumbres' supuestamente tradicionales cristalizadas, inmóviles e impasibles frente al devenir histórico sino como diferencia de meta y perspectiva por parte de una comunidad o un pueblo."

La radicalización de la diferencia es la liberación de su fuerza contenida por las redes de la diversidad cultural. Es pensarla como acontecimiento (pensar relaciones, devenires, poderes en escena), algo que no puede menos que desestabilizar lo estabilizado. Desestabilizar el canon arqueológico: ese podría ser el propósito mínimo de una tradición emergente que descree, se aparta, de la arqueología multicultural. Como escribió Arturo Escobar (1996: 39) sobre su libro contra el desarrollo, "el propósito del análisis es contribuir a liberar el campo discursivo para que la tarea de imaginar alternativas pueda comenzar." Puesto que habitamos mundos naturalizados — creados por la hegemonía cultural, social, política, económica de un sistema, de una clase, de una cosmología - tratar de habitar mundos desnaturalizados no es una empresa fácil pero seguramente tampoco es imposible. Primero hay que hacerlos -o deshacerlos: liberar el campo discursivo. Esa (des)hechura es tarea de la irrupción del acontecimiento: aquello que es, deviene, vive.

\section{Nota}

1. Pero no todos están convencidos de este abandono. Por ejemplo, la Canciller alemana Angela Merkel declaró a fines de 2010 que los esfuerzos de su país por construir una sociedad multicultural habían "fracasado completamente" y atribuyó el fracaso a los inmigrantes no integrados (véanse los prolijos reportes de prensa al respecto del 16 de octubre de ese año). En Inglaterra los políticos conservadores atacan el multiculturalismo porque divide y distinguen "entre la nacionalidad definida por la cultura y aquella definida por los derechos políticos" (Wright 2007:134). Sin embargo, quizás no sea equivocado decir que la mayor parte de las sociedades postmodernas acepta la co-existencia multicultural de lo diverso.

\section{REFERENCIAS Bibliográficas}

Atalay, S. (2008): Multivocality and indigenous archaeologies. Evaluating multiple narratives: beyond nationalist, colonialist, imperialist archaeologies (Junko Habu, Clare Fawcett y John M. Matsunaga, eds.), Springer, Nueva York: 29-44.

BRIONES, C. (2005): (Meta) cultura del Estado-nación y estado de la (meta) cultura. Universidad del Cauca, Popayán.

Brubaker, R.; Cooper, F. (2000): Beyond 'identity.' Theory and Society, 29(1): 1-47.

Colwell-Chanthaphomh, C.; Ferguson, T.J.; Lippert, D.; McGuire, R.; Nicholas, G.; Watkins, J.; Zimmerman, L. (2010): The premise and promise of indigenous archaeology. American Antiquity, 75(2): 228-238.

Escobar, A. (1996): La invención del Tercer Mundo. Norma, Bogotá.

FABIAN, J. (1990): Presence and representation: the other and anthropological writing. Critical Inquiry, 16: 753772.

Gosden, C. (2001): Potscolonial archaeology. Issues of culture, identity, and knowledge. Archaeological theory today (Ian Hodder, ed.), Polity Press, Oxford: 241-261.

Hale, C. (2002): Does multiculturalism menace? Governance, cultural rights and the politics of identity in Guatemala. Journal of Latin American Studies, 34: 485-524.

HAMILAKIS, Y. (2011): Archaeological ethnography: a multitemporal meeting ground for archaeology and anthropology. Annual Review of Anthropology, 40: 399-414. 
Martín, J. (2000): El futuro que habita la memoria. Museo, memoria y nación (Gonzalo Sánchez y María Emma Wills, eds.), Museo Nacional, Bogotá: 33-63.

Moshenska, G. (2009): What is Public Archaeology? Present Pasts, 1: 46-48.

Ramos, A. (1994): From eden to limbo: the construction of indigenism in Brazil. Social construction of the past (George Bond y Angela Gilliam, eds.), Routledge, Londres: 74-88.

Rosaldo, R. (1993): Culture and truth. The remaking of social analysis. Routledge, Londres.

SEgATO, R.L. (2007): La nación y sus otros. Raza, etnicidad y diversidad religiosa en tiempos de políticas de la identidad. Prometeo, Buenos Aires.

Sмiтн, C.; Wobst, M. (eds.) (2005): Indigenous archaeologies: decolonizing theory and practice. Routledge, Londres.

TAYLOR, C. (1993): La política del reconocimiento. Fondo de Cultura Económica, México.

UlloA, A. (2004): El nativo ecológico. Instituto Colombiano de Antropología e Historia, Bogotá.

Watkins, J. (2000): Indigenous archaeology. American Indian values and scientific practice. Altamira Press, Walnut Creek.

Wright, S. (2007): La politización de la "cultura." Constructores de otredad. Una introducción a la antropología social y cultural (Mauricio F. Bovin, Ana Rosato y Victoria Arribas, eds.), Antropofagia, Buenos Aires: 128141.

Žı̌̌EK, S. (1998): Multiculturalismo o la lógica cultural del capitalismo multinacional. Paidós, Buenos Aires. 